Abstracta Iranica Abstranica

Revue bibliographique pour le domaine irano-aryen

Volume 27 | 2006

Comptes rendus des publications de 2004

\title{
The Caspian Sea in the Twenty-First Century. Bethesda, MD, Ibex, 2003, 182 p.
}

\section{Bayram Balci}

\section{(2) OpenEdition}

1 Journals

\section{Édition électronique}

URL : http://journals.openedition.org/abstractairanica/6592

DOI : 10.4000/abstractairanica.6592

ISSN : 1961-960X

Éditeur :

CNRS (UMR 7528 Mondes iraniens et indiens), Éditions de l'IFRI

\section{Édition imprimée}

Date de publication : 15 mai 2006

ISSN : 0240-8910

\section{Référence électronique}

Bayram Balci, «The Caspian Sea in the Twenty-First Century. Bethesda, MD, Ibex, 2003, 182 p. », Abstracta Iranica [En ligne], Volume 27 | 2006, document 349, mis en ligne le 02 janvier 2007, consulté le 25 septembre 2020. URL : http://journals.openedition.org/abstractairanica/6592 ; DOI : https:// doi.org/10.4000/abstractairanica.6592

Ce document a été généré automatiquement le 25 septembre 2020.

Tous droits réservés 


\title{
The Caspian Sea in the Twenty-First Century. Bethesda, MD, Ibex, 2003, $182 \mathrm{p}$.
}

\author{
Bayram Balci
}

1 Comme sa dénomination la plus commune en Occident ne l'indique pas, la mer Caspienne n'en est pas nécessairement une. En effet, la désintégration de l'URSS et l'apparition sur ses rives de nouveaux Etats a remis en question le statut juridique de la Caspienne. Au-delà des débats des géographes sur la nature lacustre ou maritime de cette étendue d'eau, l'Iran et, aujourd'hui, la Russie, le Kazakhstan, l'Azerbaïdjan et le Turkménistan se disputent le partage des ressources qu'elle renferme ou sur lesquelles elle s'étale. Car ce sont moins les revenus de la pêche qu'ils visent que la manne issue de l'exploitation des sous-sols riches en hydrocarbures. L'auteur, docteur en droit international, s'en tient strictement à un point de vue de juriste. Il énonce les données de cette dispute en revenant d'abord sur le statut de la Caspienne avant la chute de l'URSS, régulé par les traités de 1921 et 1940. Ces deux textes signés à l'époque par les deux seuls pays riverains, Union Soviétique et Iran, régulaient essentiellement les droits de passage, la libre circulation des bâtiments des deux pays et délimitaient les zones de pêche. Les explorations du sous-sol par les puissants consortiums pétroliers depuis une quinzaine d'années ayant révélé des réserves considérables en gaz et pétrole, les nouveaux acteurs régionaux réclament aujourd'hui leur part de ce gâteau. Dans des chapitres succincts, l'A. présente la position de chacun : la Russie considère toujours la Caspienne comme un lac fermé et a sollicité, le 5 octobre 1994, un arbitrage des Nations Unies tout en menaçant ses nouveaux voisins de représailles en cas d'initiatives unilatérales contraires aux traités de 1921 et 1940. L'Iran campe sur une ligne proche des Russes. Face à eux, l'Azerbaïdjan et le Turkménistan se sont rangés, à quelques nuances près, du côté du Kazakhstan - ce dernier réclamant pour la Caspienne l'application de la convention de la mer de 1982 pour obtenir la délimitation des eaux territoriales et zones d'exploitation économiques de chacun, au prétexte que la Caspienne est reliée aux océans par les canaux de la Volga jusqu'au golfe de Finlande. La bataille n'ayant lieu jusqu'à présent que sur le terrain juridique, l'A. s'en tient aux 
textes, qui forment d'ailleurs l'essentiel des annexes, soit plus de la moitié du volume. Et c'est là le principal reproche que l'on peut lui faire. Son résumé froid et linéaire d'une question déjà débattue maintes fois par autant de juristes que de géopoliticiens, géographes, historiens, diplomates et autres, n'apporte aucun élément réellement nouveau et fait l'impasse des autres dimensions de la querelle, qui sont pourtant indissociables des enjeux économiques, comme l'aspect humain des communautés riveraines vivant grâce à la Caspienne et les dégâts environnementaux passés, présents et futurs liés à son usage par les hommes. Les étudiants en droit trouveront l'exposé d'un cas d'école rassemblé dans un volume avec en annexes les textes relatifs au litige, même si l'on regrette l'absence dans ce manuel incomplet de cartes thématiques localisant la répartition des ressources marines et sous-marines connues ou estimées, ainsi que les revendications respectives des différents Etats en terme d'eaux territoriales.

INDEX

Thèmes : 13.1. Iran

\section{AUTEURS}

BAYRAM BALCI

IFEAC - Tachkent 